\title{
Purple Urine Bag Syndrome in a Male Patient with Chronic Hemodialysis
}

\author{
Hakan Koçoğlu, Betül Yıldırım, Yıldız Okuturlar, Mehmet Hurşitoğlu, Özlem Harmankaya
}

Department of Internal Medicine, Bakırköy Dr. Sadi Konuk Training and Research Hospital, İstanbul, Turkey

A 78-year-old male patient who had an indwelling urinary catheter because of benign hyperplasia of the prostate and who had been receiving hemodialysis twice a week due to endstage renal disease was admitted to our hospital complaining of three days of purple urine color (Figure 1). His medications included beta blocker, anti-aggregant, erythropoietin, piracetam and calcitriol therapies. A urine analysis was performed; the results were as follows: $\mathrm{pH}$ : 8.0, density: 1012, leukocyte esterase: $(++)$, leukocyte: 11/HPF (high power field), erythrocyte: $4 / \mathrm{HPF}$ and nitrite: negative. The diagnosis of purple urine bag syndrome (PUBS) was made. Treatment with ceftriaxone $2 \mathrm{~g}$ /day intravenously (IV) was started immediately on an empirical basis, and the catheter was replaced. Extendedspectrum beta-lactamase-positive Escherichia coli was isolated in urine culture, and the antibiotherapy was changed to imipenem/cilastatin $250 \mathrm{mg}$ IV twice daily. On the fifth day of treatment, the patient's urine color returned to normal, and a urine sample was negative for leukocyte esterase.

Discoloration of urine is important in clinical diagnosis and treatment. PUBS stands for purple discoloration of the urine occurring in patients with long-term urinary catheterization. The interesting point of this syndrome is that the urine itself is unchanged in color but the only change in color is within the bag itself. Reported risk factors of PUBS include chronic urinary catheterization, old age, female gender, dehydration, bedridden, constipation, advanced chronic kidney disease, alkaline or acidic urine, and PVC catheters and bags (1-3). Briefly, pathogenesis is related to sulfatase and/or phosphatase enzyme carrying bacteria (such as Klebsiella, E. Coli, Morganella, Pseudomonas, Enterobacter, Proteus) (1) that leads to metabolize indican into indigo (blue pigment) and indirubin (red pigment) in the urine which results purple discoloration of urine in the plastic of the urine bag (4).

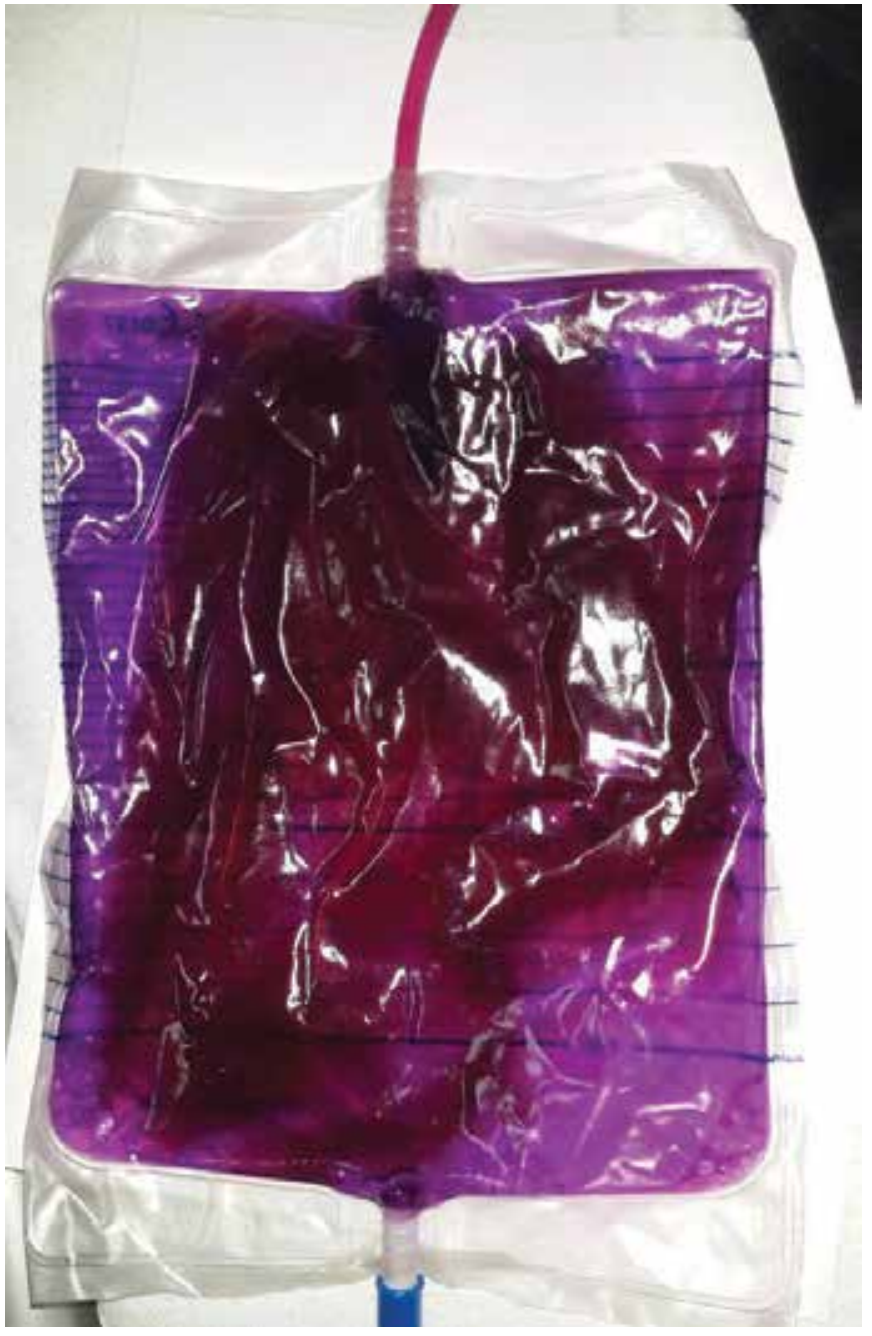

FIG. 1. Purple discoloration of the urine when the patient was admitted to the hospital

This study has been presented at the $14^{\text {th }}$ European Congress of Internal Medicine, 14-16 Octover 2015, Moscow, Russia.

Address for Correspondence: Dr. Hakan Koçoğlu, Department of Internal Medicine, Bakırköy Dr. Sadi Konuk Training and Research Hospital, İstanbul, Turkey Phone: +905063809215 e-mail: dr.hakankocoglu@gmail.com

Received: 31 August $2015 \quad$ Accepted: 24 February $2016 \quad$ DOI: 10.5152/balkanmedj.2016.151140

Available at www.balkanmedicaljournal.org

Koçoğlu H, Yıldırım B, Okuturlar Y, Hurșitoğlu M, Harmankaya Ö. Purple urine bag syndrome in a male patient with chronic hemodialysis. Balkan Med J 2016;33:717-8. 
Purple urine bag syndrome actually is not very rare, especially in chronically debilitated patients and in elderly patients who also tend to have several comorbidities $(1,2)$. PUBS is essentially harmless, although it can be alarming to both patients and doctor. The underlying urinary tract infection can lead to serious consequences. Because of PUBS itself is a benign and harmless condition, therapy should be targeted at the causative medical problem rather than at PUBS itself.

Purple urine bag syndrome is usually associated with higher incidence of mortality and morbidity than urinary tract infection alone (5). This may be caused by the fact that patients with PUBS could be more prone to developing complications of infection, such as urosepsis, as they frequently have several or serious comorbidities. Thus, physicians should be aware of the fact that this syndrome could be a signal for a urinary tract infection which is needed immediately to start an aggressive treatment (5).

\section{Ethics Committee Approval: N/A.}

Informed Consent: N/A.

Peer-review: Externally peer-reviewed.

Author contributions: Concept - H.K., B.Y., Y.O., M.H., Ö.H.; Design - H.K., B.Y., Y.O.; Supervision - M.H., Ö.H.; Resource H.K., B.Y., Y.O.; Materials - M.H., Ö.H.; Data Collection and/or Processing - H.K., B.Y.; Analysis and/or Interpretation - Y.O., M.H.,
Ö.H.; Literature Search - Y.O., M.H., Ö.H.; Writing - H.K.; Critical Reviews - H.K., B.Y., Y.O., M.H., Ö.H.

Conflict of Interest: No conflict of interest was declared by the authors.

Financial Disclosure: The authors declared that this study recevied no financial support.

\section{REFERENCES}

1. Mantani N, Ochiai H, Imanishi N, Kogure T, Terasawa K, Tamura J. A case-control study of purple urine bag syndrome in geriatric wards. J Infect Chemother 2003;9:53-7. [CrossRef]

2. Shiao CC, Weng CY, Chuang JC, Huang MS, Chen ZY. Purple urine bag syndrome: a community-based study and literature review. Nephrology (Carlton) 2008;13:554-9. [CrossRef]

3. Yang CJ, Lu PL, Chen TC, Tasi YM, Lien CT, Chong IW, et al. Chronic kidney disease is a potential risk factor for the development of purple urine bag syndrome. $J$ Am Geriatr Soc 2009;57:1937-8. [CrossRef]

4. Lin CH, Huang HT, Chien CC, Tzeng DS, Lung FW. Purple urine bag syndrome in nursing homes: ten elderly case reports and a literature review. Clin Interv Aging 2008;3:729-34. [CrossRef]

5. Agapakis D, Massa E, Hantzis I, Paschoni E, Satsoglou E. Purple Urine Bag Syndrome: a case report of an alarming phenomenon. Hippokratia 2014;18:92-4. 